\title{
Cross-cultural research in management control systems design: a review of the current state
}

\author{
Graeme L. Harrison, Jill L. McKinnon \\ School of Economic and Financial Studies, Macquarie University, New South Wales 2109, Australia
}

\begin{abstract}
This paper reviews cross-cultural research in management control systems (MCS) appearing in English-language journals over the past 15 years. The objectives are to examine these studies for their convergence or otherwise with respect to the state of our understanding of cultural effects on MCS design, and to analyse their theoretical and methodological strengths and weaknesses to guide future research. The review identifies four major weaknesses seen to apply collectively to this research: (i) a failure to consider the totality of the cultural domain in theoretical exposition; (ii) a tendency to not consider explicitly the differential intensity of cultural norms and values across nations; (iii) a tendency to treat culture simplistically both in the form of its representation as a limited set of aggregate dimensions, and in the assumption of a uniformity and unidimensionality of those dimensions; and (iv) an excessive reliance on the value dimensional conceptualization of culture, which has produced a highly restricted conception and focus on culture, and placed critical limits on the extent of understanding derived from the research to date. (C) 1999 Elsevier Science Ltd. All rights reserved.
\end{abstract}

A developing body of research in recent years has been directed at understanding the relation between national culture and the design of management control systems (MCS) in different countries. This research has gained increasing prominence for two reasons. First, it is important to the business community. With increasing globalization has come the opportunity and necessity for companies, which may have operated previously in only their home country, to establish international operations. The question of whether those companies can transport their domestic MCS overseas, or whether they need to redesign the MCS according to the cultural imperatives of the overseas nations, is of considerable practical significance. The research is also important to the academic community. The design of MCS has been a mainstream issue in accounting research for many years. However, despite some early recognition of the importance of culture (French et al., 1960 for example, with respect to budgetary participation), the great majority of MCS research has been conducted within single nations. In the absence of examination of the influence of culture, models of MCS design are under-specified.

Although cultural research on MCS design is increasing, it remains relatively recent in that it dates mainly from the 1980s, and may still be considered exploratory. As such, it seems an apposite time to review the studies to date with respect to the state of our understanding of cultural effects on MCS design, and to analyse those 
studies' theoretical and methodological strengths and weaknesses with the purpose of guiding future research. ${ }^{1}$

This paper seeks to provide such a review, and is organized as follows. The first section briefly discusses the movement from the comparative international studies of MCS prior to the 1980s to the culture-theoretic studies which have predominated in the past 15 years. These latter studies are then tabulated and reviewed in aggregate, leading to the observation that while there is evidence of some convergence building with respect to the importance of culture's effect on MCS design, there are also substantive disparities among the findings. The paper then identifies, and illustrates by reference to specific studies, four major weaknesses in the research which may serve to explain some of the disparities and to inform future research. These weaknesses are: (i) a failure to consider the totality of the cultural domain in the theoretical development of some studies; (ii) an almost universal tendency to not consider explicitly the differential intensity of cultural norms and values across nations, resulting in a failure to distinguish between core and peripheral values in theoretical exposition; (iii) a tendency to treat culture simplistically both in the form of its representation by a limited set of aggregate value dimensions, and in the assumption of a uniform and unidimensional nature of those dimensions; and (iv) an excessive reliance on the value dimensional conceptualization of culture which has produced a highly restricted conception and focus on culture, and placed critical limits on our extent of understanding.

The research reviewed is limited to studies appearing in the main English-language research journals. These studies have predominantly focused on comparisons between a variety of Asian nations and the Anglo-American nations of the U.S.A. and Australia, although one study in the review (Frucot \& Shearon, 1991) focused on Mexico. While one reason for the concentration

\footnotetext{
1 Readers may also be interested in two other reviews of cross-cultural studies in related areas in recent years; Smith's (1992) survey of such studies of organizational behaviour, and Gernon and Wallace's (1995) survey of culture-based studies in international (financial) accounting.
}

on Asian and Anglo-American nations has been the appealing appearance of substantive differences between Eastern and Western cultures, nonetheless the geographic scope restriction of such a concentration has to be acknowledged.

A further restriction on the scope of the paper is imposed by a specific characteristic of the studies which form the body of research in this area. This characteristic is that the studies have been informed almost exclusively by the value-dimensional conception of culture in the cross-cultural psychology literature, and, since the late 1980s, have been even further restricted and narrowed in focus through an almost total adoption of the (psychology based) work of Geert Hofstede. As a consequence, the research has ignored other relevant literatures and perspectives on culture, notably those in sociology, anthropology and history. This issue is identified as the fourth weakness in the extant research and is returned to later in the paper in that capacity. However, it must be acknowledged at the outset that the body of studies reviewed for this paper is subject to this narrowness of focus, and that the paper itself is therefore similarly restricted in the scope of its review and analysis.

\section{From comparative international to culture-the- oretic research}

Early comparative international studies, such as Whitt (1979), which found differences in the level of budgetary participation between U.S. and Mexican companies, and Chiu and Chang (1979), which found differences in the use of management accounting techniques between U.S. and Taiwanese companies, were criticised for their absence of an underlying theory of culture. A similar criticism applies to the later Daley, Jiambalvo, Sundem and Kondo (1985) study of attitudes of Japanese and U.S. controllers and managers towards aspects of budgeting and control systems design. The criticism was, that although these studies purported to be cross-cultural, they were essentially atheoretic about what culture was, and therefore silent on what it was about culture that was associated with the observed national differences. The criticism 
was expressed variously as culture being treated as "a packaged, unexamined variable" (Rohner, 1984, p. 111), "an unspecified independent construct" (Bhagat \& McQuaid, 1983, p. 685), a "black box" (Pascale, 1978, p. 107), and a "residual category to explain things not accounted for elsewhere" (Kraut, 1975, p. 544).

Based on this criticism, advocates of cross-cultural research in the early 1980s were calling for an "unbundling" of the cultural variable into its subcomponents, which could then provide the basis for theoretical explanations of relations between culture and other variables of concern. Bhagat and McQuaid (1983, p. 685), for example, required that differences in dependent variables "should not be attributed to differences in culture unless and until components of the cultural construct have been satisfactorily specified in the study". Similarly, Child (1981, p. 330) argued, that for a study to be effectively cross-cultural, it needed to delineate theoretically which subcomponents of culture were likely to be determinants of the organizational and behavioural variables at issue, and to postulate those associations in advance of empirical study.

An example of the "unbundling" of culture into components is the work of Hofstede (1980) who, from his survey of employee attitudes in the worldwide subsidiaries of IBM, disaggregated culture into four norm values (which he termed "dimensions" of culture): power distance (hereafter abbreviated to PD), individualism (IDV), uncertainty avoidance (UA) and masculinity (MAS). Subsequent research identified a fifth norm value, Confucian Dynamism (CD) (Hofstede \& Bond, 1988). Hofstede (1984) ranked 50 nations and three regional groupings on each of the first four of these dimensions, or components, and Hofstede and Bond (1988) ranked 22 nations on the Confucian Dynamism component. While there are alternative value dimensional schema of culture developed both before and after Hofstede's work (e.g. Parsons \& Shils, 1951; Kluckhohn \& Strodtbeck, 1961; Triandis, 1995; Smith, Dugan \& Trompenaars, 1996), Hofstede's typology, together with the country rankings contained in his work, has been extensively, almost exclusively, adopted by cross-cultural researchers in MCS in recent years.

\section{Cross-cultural MCS studies from 1980 to 1996: convergence and disparity}

The literature search for this paper yielded 20 cross-cultural studies of MCS design appearing in main English-language research journals since the early 1980s. These studies are listed in chronological order in Table 1, which shows the countries studied, sample size, research method, MCS characteristics, and the cultural dimensions and societal values relied on in each study.

As part of our review, we sought to assess the extent of convergence or disparity in the studies in terms of whether they provided evidence for or against culture's effect on MCS. The criterion was whether the results in each study supported or did not support a culture-MCS association, judged against the significance level imposed by the original authors. ${ }^{2}$ While this review allowed an assessment of reasonable convergence of support for the effect of culture across a wide range of MCS characteristics, such an assessment must be guarded given the substantial difficulties we encountered in undertaking it.

First, as Table 1 shows, a great variety of MCS and organizational characteristics has been examined, and there has been very little replication or confirmatory work done on those characteristics. Even where more than one study has examined the "same" MCS characteristic, the operational definition of that characteristic has often varied, or insufficient definition has been provided to allow some assurance of commonality. An example is the MCS characteristic of formalization/rules and procedures, which has been operationalized in a variety of ways in the seven different studies shown in Table 1 as examining this characteristic. Second, different cultural dimensions have sometimes been drawn on in different studies to support the same culture-MCS linkage, and, even where the same cultural dimensions have been used, different theories have sometimes been invoked.

\footnotetext{
${ }^{2}$ No assessment of the specific nature of convergence or disparity with respect to prescriptions or proscriptions of MCS design in different nations is attempted in this paper. Rather, the focus is on the culture-MCS hypothesis generally, and on the theoretical and methodological issues relevant to that hypothesis.
} 
Table 1

Cross-cultural studies of management control system design post 1980

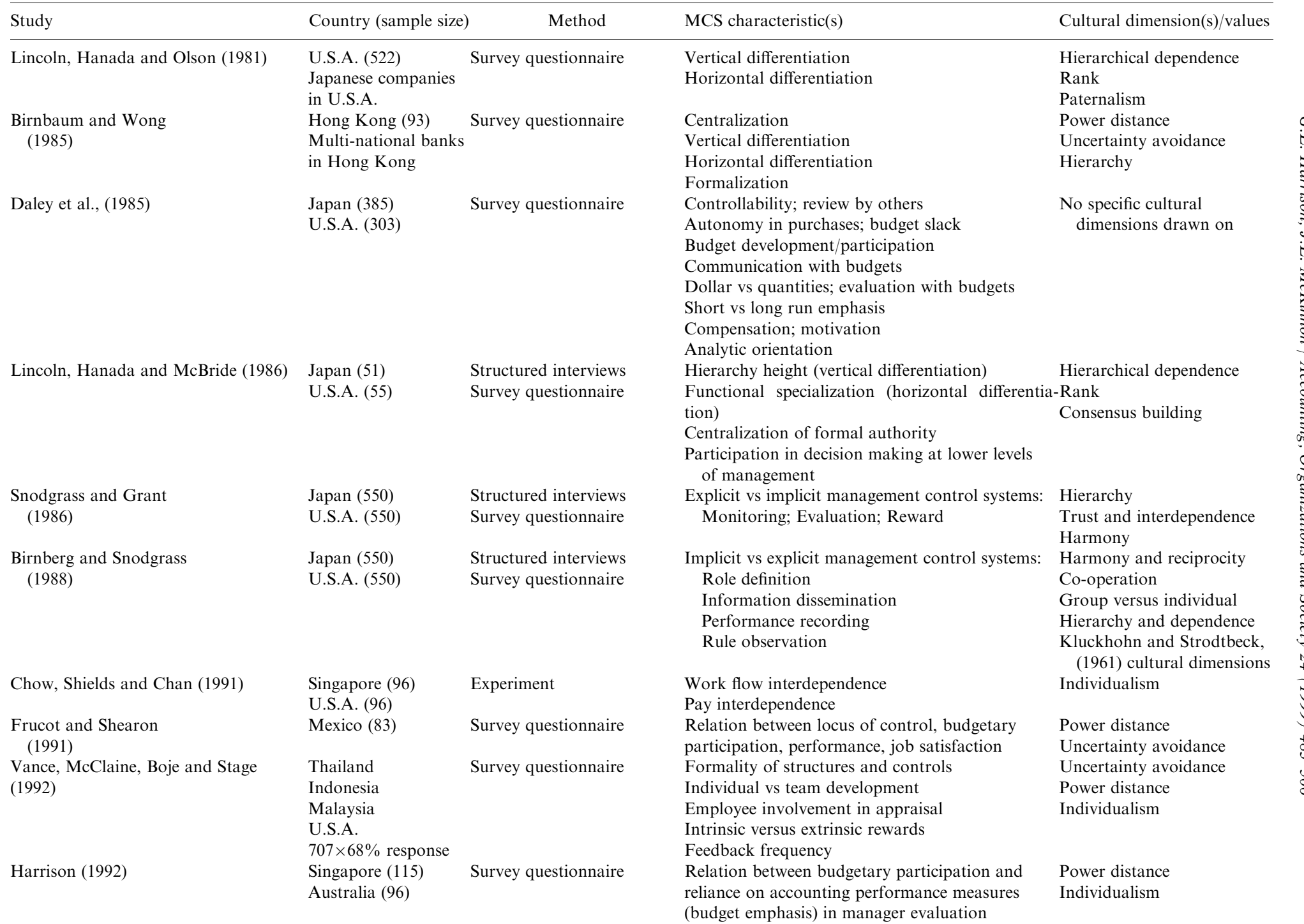


Harrison (1993)

Ueno and Sekaran

(1992)

Ueno and Wu (1993)

Harrison, McKinnon,

Panchapakesan and Leung (1994)

U.S.A. (104)

Australia (140)

Singapore (65)

Hong Kong (55)

Chow, Kato and Shileds (1994)

U.S.A. (54)

Japan (39)

Lau, Low and Eggleton (1995)

Merchant, Chow and Wu (1995)

Taiwan (23)

U.S.A. (54)

Singapore (125)

Taiwan (155)

Chow, Shield and Wu (1996a)

Chow, Kato and Merchant (1996b)

U.S.A. (54)

Japan (28)
Survey questionnaire

Survey questionnaire

Survey questionnaire

Experiment

Experiment

Survey questionnaire

Open-ended,

in-depth interviews

Survey questionnaire

Survey questionnaire

Survey questionnaire
Reliance on accounting performance measures

in superior evaluative style

Power distance

Individualism

Formalizing communication and coordination in Individualism

budgetary planning processes

Uncertainty avoidance

Budgetary slack

Controllability in performance evaluation

Length of time horizon in performance evaluation

Structure of budget planning process

(procedures and rules)

Time horizon in budget planning process

Organizational design:

Decentralization

Power distance

Responsibility centres

Individualism

Confucian dynamism

Planning and control:

Use of quantitative techniques

Planning time horizon

Group vs individual decision making

Formalization

Organizing:

Environmental uncertainty, Hierarchy height,

Centralization, Interdependencies,

Formal rules

Formal

Top down planning, Standard difficulty

Evaluating:

Controllability filters, Relative evaluation

Rewarding:

Individual-based rewards, Preset pay

Relation between budget emphasis, budgetary Power distance

participation and task characteristics affectingIndividualism

related tension and performance

Size of performance dependent reward

Collectivism

Long term performance incentives

Subjective vs objective performance evaluations

Confucian dynamism

Uncertainty avoidance

Masculinity

Participation in budget setting

Power distance

Participation in evaluation

Decentralization, Structuring of activities,

Participative budgeting, Standard tightness,

Performance rewards, Controllability filters,

Reliance on accounting performance measures,

Participative performance evaluation

Power distance

Individualism

Confucian dynamism

Uncertainty avoidance

Control tightness

Masculinity

Procedural controls

Collectivism

Power distance

Controls through directives at meetings Uncertainty avoidance 
Third, although the survey questionnaire has been the predominant (almost universal) method used to date, differences in sample sizes, managerial level and location of respondents, and the degree to which other variables are controlled for, all contribute to a difficulty in assessing convergence or disparity in the findings. The failure of Vance et al. (1992) to control for the backgrounds of respondents in their study is an example. Vance et al. (1992) studied perceptions of management performance systems in the U.S., Thailand, Indonesia and Malaysia, expecting them to differ between the U.S. and the three Asian nations. While some significant differences were found in that comparison, it was also found, contrary to expectations, that there was as much difference between the three Asian nations themselves as there was between those nations and the U.S. A methodological cloud on the Vance et al. (1992) results is the considerable systematic variations in the backgrounds of the respondents from the Asian nations, particularly in the proportion who had studied or worked abroad.

A further example is Birnbaum and Wong (1985), who surveyed 93 Chinese managers in 20 multinational banks in Hong Kong to examine the relation between job satisfaction and four elements of organizational structure; vertical and horizontal differentiation, centralization and formalization. The home country of the banks was used to proxy for culture, and the banks were classified into a cultural matrix based on Hofstede's (1980) rankings for PD and UA. However, there was substantial variation in the distribution of respondents across the cells. The data were dominated by a concentration of the sample (64 out of 93) in the low PD/low UA cell, with low numbers $(12,13$ and 14) in the other three cells.

While our assessment of the studies in Table 1 showed evidence of some convergence building for culture's effect on MCS characteristics (with the caveat of the issues in the preceding paragraphs), it also showed substantive disparities among findings, with a number of studies reporting the absence of a cultural effect and others producing equivocal results. The remainder of this paper identifies several key issues or weaknesses arising from analysis of the research, which may help both to explain some of the disparity in the results to date, and to guide future research. These weaknesses were noted earlier as: (i) a failure to consider the totality of the cultural domain in theoretical exposition; (ii) a tendency to not consider explicitly the differential intensity of cultural norms and values across nations; (iii) a tendency to treat culture simplistically; and (iv) an excessive reliance on the value dimensional conceptualization of culture. Each of these weaknesses is now discussed in turn.

The first three issues relate to deficiencies and weaknesses with the way in which cross-cultural MCS research to date has operationalized culture within a functionalist conception based on norms and values. Ways in which future research may be enhanced within this conception are proposed. The fourth issue relates to limitations imposed by this conception of culture, and leads to discussion of how other conceptions from the sociology, anthropology and history literatures may allow future research to open up new understandings of MCS in cultural contexts.

\section{Failure to consider the totality of the cultural domain: omitted dimensions}

As Table 1 shows, there has been a tendency in many of the cross-cultural MCS studies to select some cultural dimensions for use in the theoretical specification of the study, and to ignore others. While all dimensions do not need to be present in the theory specification, they are of course present in the empirics, in that respondent samples from different societies bring with them the totality of those societies' cultures, not just the ones drawn on in the theory. Consequently, the choice to omit a dimension from the theoretical exposition of the study must be taken on an equally theory-driven evaluation of the irrelevance of the dimension to the dependent variable or relation at issue. Chow et al. (1991) is an example of good practice here. Although they relied only on IDV in their experimental study of workflow and pay interdependence in Singapore and the U.S., they demonstrated that IDV was the most relevant dimension for the MCS characteristic they 
studied. Alternatively, the omitted dimension must be otherwise attended to in the study's methodology; for example, by matching the cultures under study on this dimension. Harrison $(1992,1993)$ is an example of where sample countries were matched on dimensions not implicated in the theory. While there are examples of good practice in the research reviewed, there are also instances where the choice of dimensions and countries has not been adequately motivated, with the result that a partial explanation for some of the disparity in the research findings to date appears to lie in the theoretical omission of relevant dimensions.

Frucot and Shearon (1991) is an example. They focused on budgetary participation, and sought to examine the cross-cultural generalizability of Brownell's (1982) study of participation among U.S. managers. They hypothesized that Brownell's results might not generalize to Mexico, on the grounds that Mexican society was ranked (by Hofstede, 1980) as higher on PD and UA than the U.S., and that high rankings on these dimensions would be associated with a preference for an autocratic, rule-based organization, and for less participation. Frucot and Shearon's results were essentially contrary to their expectations. Although the results suggested that some cultural effect might be present in managerial level and firm ownership subsets of their samples, their main finding was that no cultural effect was present, and that Brownell's U.S. results essentially did generalize to Mexico.

However, although Frucot and Shearon noted that the U.S. and Mexico also differed on the cultural dimension of IDV (with Mexico more collectivist), they did not formally incorporate the likely effects of such a difference into their theory. Yet a relatively substantial amount of literature suggests an association between collectivism and a preference for participation (Lincoln \& McBride, 1987; Chow et al., 1991, p. 211; Harrison, 1992). While concurring theoretically with Frucot and Shearon that PD is an important cultural influence on reactions to participation, with high (low) PD associated with negative (positive) reactions, Harrison (1992) argued that IDV is also an important influence which cannot be ignored in theoretical specification, with low (high) IDV being asso- ciated with positive (negative) reactions. Thus, Harrison hypothesized and found that if a society were both high PD and low IDV (as is Mexico) or low PD and high IDV (as is the U.S.), the potential effects of participation would be similar in and hence generalizable to both societies. As this is the result Frucot and Shearon essentially found, what they interpreted as a non-cultural result based on the theoretical inclusion of PD and UA alone, may, in fact, be quite the opposite and evidence of a culturally consistent finding with the theoretical inclusion of IDV. ${ }^{3}$

A methodological concern with the Frucot and Shearon study is that they did not measure PD and UA to provide support that their respondent sample was reflective of the cultural dimensions they were asserting for Mexico. While it may be argued that such measurement is not necessary, on the grounds that culture's effects are present in the location of the individual in the society manifesting that culture, nonetheless it seems sensible to assess whether the respondent sample is consistent in its collective values with that of the society it is being used to represent. This is a methodological concern widely applicable to the extant research, in that few studies (exceptions are Chow et al., 1991; Harrison, 1992, 1993; Harrison et al., 1994; and O'Connor, 1995) have formally measured the cultural dimensions on which they rely for their respondent samples.

A second example of omitted dimensions is Birnbaum and Wong (1985), who drew on Hofstede's dimension of UA to hypothesize that Hong Kong nationals would prefer lower levels of horizontal differentiation than (by implicit contrast) U.S. nationals. They formed this hypothesis because "Hofstede (1980, p. 315) found that Hong

\footnotetext{
3 This point needs to be made cautiously because Harrison (1992) used Singapore and Australia to proxy for high PD/low IDV and low PD/high IDV cultures, respectively. Thus, the conclusion about the cultural consistency of Frucot and Shearon's findings relies on the assumption that the intensity or relative importance of PD and IDV are the same in their effects on participation in the nations studied by Harrison (1992) (Singapore and Australia) and by Frucot and Shearon (1991) (Mexico, and by implicit comparison, the U.S.). This assumption may not hold as the following section dealing with the issue of core and peripheral values will demonstrate.
} 
Kong employees had a strong preference for low levels of uncertainty avoidance, which is strongly associated with low levels of horizontal differentiation (Hofstede, 1980, p. 187)" (Birnbaum \& Wong, 1985, p. 265). Birnbaum and Wong's results failed to support their hypothesis. This is not surprising, however, in that their hypothesis was developed by the selected and abstracted juxtaposition of two separate quotes from Hofstede, without consideration of other cultural attributes of Hong Kong society which are highly likely to affect preferred levels of horizontal differentiation in that country. Birnbaum and Wong's theoretically uncritical selection of UA obscured a number of other important considerations, including, most notably in this instance, the evidence from other research. The anomalous situation arises for Birnbaum and Wong whereby, although they motivate their study from Lincoln et al. (1981), they ignore the finding of that study in the formulation and assessment of their theory. Lincoln et al. (1981) found a low level of horizontal differentiation in Japan, a nation where UA is high, whereas Birnbaum and Wong hypothesized a low level of horizontal differentiation in Hong Kong where, and because, UA is low.

\section{Differential intensity of cultural norms and values: core and peripheral values}

Table 1 shows that considerable research attention has been focussed on Anglo-American (particularly the U.S. and Australia) vs Asian (particularly Japan, Singapore and Hong Kong) societies, and has relied substantially on differences across those societies in PD, IDV and UA. Because the Anglo-American cluster nations are typically regarded as higher IDV and lower PD than the Asian ones, the studies have tended to assume that IDV and PD are values maintained with equal intensity and importance in each of these nations. The extreme instance of this assumption is Harrison (1992), who, as noted above, predicated his hypothesis that responses to participation would be similar in a low $\mathrm{PD} /$ high
IDV culture and a high PD/low IDV one, on the argument that these composite cultures comprised equal and offsetting levels of PD and IDV with respect to their impact on participation. That is, he assumed that the weight and intensity of the dimensions of PD and IDV in the two nations he studied were equal. However, as Lachman, Nedd and Hinings (1994, p. 14) argue:

...not all values are equally important (in all nations), or have the same impact in regulating behavior. Cultural values ought to be differentiated in terms of the impact they have in legitimizing and directing choices of modes of organizing and patterns of managerial behavior.

Lachman et al. (1994, p. 41) go on to argue that "the impact cultural values have is determined by their centrality within the value system of a cultural setting more than by their prevalence in this setting" (emphasis added). They distinguish values which are central to a culture as core, and those which are not as peripheral, and contend (p. 41) that "the more important and central the value, the stronger will be its impact and the more consequential it will be for differences in organizational and managerial practices". By extension, the more central a value, the more enduring and resistant to change it is, both across time and in competition with contrary values. By contrast, peripheral values are less stable and less enduring, with members of the society either manifesting different levels of attachment to them, or even disregarding them (Lachman et al., 1994, p. 42).

The concept of core versus peripheral values may explain some of the disparity in existing findings from the cultural studies of MCS, and may be useful in guiding future research. First, it may be a potential explanation of the reported failure to find cultural effects in the results of Ueno and Sekaran (1992) (and, by extension, Ueno and Wu (1993), as both papers report the same study), and Birnbaum and Wong (1985).

As Table 1 shows, Ueno and Sekaran (1992) studied six budget control practices in manufacturing companies in Japan and the U.S. The results were as hypothesized for four of the six 
practices. Compared to Japanese companies, U.S. companies (i) used formal communication and coordination in budget planning processes, (ii) built slack into budgets, and (iii) practised controllability of budgets to a greater extent, and (iv) used long-term evaluation horizons to a lesser extent. The remaining two hypotheses that Japanese companies would structure their budget planning processes, and use long time horizons in those processes to a greater extent than U.S. companies were not supported. The supported four were premised on differences in IDV between Japan and the U.S., and the unsupported two were premised on differences in UA. Similarly, Birnbaum and Wong (1985) found support for a greater preference for centralization in decision making in Hong Kong Chinese organizations (in implied comparison with the U.S.), with this cultural expectation premised on differences in PD; but found no cultural effect for other structural characteristics when the cultural expectations were premised on UA.

Ueno and Sekaran (1992) commented that there appeared to be a difference in the relative significance of IDV and UA within the national and MCS contexts of their study; a comment which may have been implicit recognition of the core versus peripheral value argument of Lachman et al. (1994). Relevant to both Ueno and Sekaran and Birnbaum and Wong is that there is evidence to suggest that IDV is a core value of both U.S. and Japanese societies, and PD a core value of Chinese society (Lachman et al., 1994, p. 49), while there is also evidence to suggest that UA may not be a core value in these societies. Although UA was identified in Hofstede's (1980) study as one of the four dimensions on which societies differed, and has been supported in other studies (Bosland, 1984), the UA dimension was not found to be present in the Chinese Value Survey (CVS) (Hofstede \& Bond, 1988), or in Smith et al.'s (1996) value dimensional analysis across 43 nations. The CVS results raise the question of whether UA is a cultural dimension relevant only to western nations (and discernible only in instruments developed with western biases), while the Smith et al. (1996) results question UA's relevance more fundamentally. Further support for the irrelevance, or at best peripheral nature of the UA value in non-western societies is the substantial variation found among Chinese-based nations on measure of this dimension. ${ }^{4}$

An implication of core versus peripheral values for research relying on value dimensional analysis is that the basis for choice of the dimensions cannot be made solely on grounds of differences in national scores on the dimensions. While we noted that Ueno and Sekaran (1992) may have implicitly recognized the issue of core versus peripheral values, that recognition was ex post and fortuitous, and arose because of the insufficient theoretical premise for their choice of IDV and UA, which was that these were the two cultural dimensions on which the U.S. and Japan are "maximally differentiated in Hofstede's empirical study" (Ueno \& Sekaran, 1992, p. 662). Hence, it was conjectured that these two dimensions "would explain ... any differences that might exist in budget control practices in the two countries" (Ueno \& Sekaran, 1992, p. 671). Their results and the Lachman et al. (1994) work demonstrate that it is not sufficient to choose cultural dimensions on the basis of their differences on Hofstede's (or others') scoring alone. Rather, such choice must also be informed by the centrality and intensity of the dimensions in the contexts of both the societies and the MCS characteristics at issue. Reinterpreting the Ueno and Sekaran (1992) and Birnbaum and Wong (1985) results in the light of core versus peripheral values suggests that those of their findings which did not support a cultural effect may not be evidence of the absence of such an effect

\footnotetext{
${ }^{4}$ On Hofstede's (1980, p. 165) country UA index (with an observed range of 8 to 112 for low to high UA), Chinese-based nations range from 8 (Singapore) through 29 (Hong Kong) to 69 (Taiwan). As an example of subsequent measures, Harrison et al. (1994) administered Hofstede's original instrument to managers in Australia, U.S., Singapore and Hong Kong. While the scores for PD and IDV were consistent with Hofstede's across all four countries for PD particularly, and IDV to a lesser extent, they were quite variant on UA for the Chinese societies. Singapore was scored at 52 in Harrison et al. compared to Hofstede's score of 8, and Hong Kong at 63 compared to 29. Similarly, Cragin (1986), cited in Smith et al. (1996, p. 121), used Hofstede's instrument with a PRC sample and found high collectivism and high power distance (in accord with Hofstede), but, in contrast to Hofstede's scores for Chinese-based cultures, found a high score for uncertainty avoidance.
} 
at all, but evidence, rather, of an invalid test of culture through the use of peripheral or irrelevant cultural values.

A second implication of the centrality of values relates to research examining whether multinational companies need to modify their domestic MCS to suit the national culture of a foreign country, or whether they can create an organizational culture in the foreign subsidiary within which their domestic MCS can be implemented. Much of the research has been premised implicitly on the former assumption, with Chow et al. (1996a) lending evidence to support this by finding, in their study of eight MCS characteristics in Japanese and U.S. organizations operating in Taiwan, that the organizations from both countries substantially modified their MCS to suit the different Taiwanese culture. By contrast, O'Connor (1995) found evidence of firms' modifying (through selection, socialization and training) the microcosmic organizational cultures of their overseas subsidiaries to suit the firms' home office MCS. This is not inconsistent with Chow et al. (1996a); rather it suggests that organizations have a choice, and that the choice is dependent on the costs of modifying the organizational culture versus those of modifying and maintaining different MCS in different nations. No research has yet examined the cost/benefit issue. However, when it does, it will need to be cognisant of the centrality of values issue. One of the criteria differentiating core and peripheral values is their resistance to change (Lachman et al., 1994, p. 41), suggesting that the costs of modifying components of organizational cultures where those components involve core national values are likely to be much greater than where they involve peripheral values.

Lachman et al. (1994, pp. 50-52) provide a matrix framework of core vs peripheral values at both organizational and national levels, and suggest abstracted strategies for organizational adaptation in each combination cell. While they suggest different strategies for each of the four cells, essentially they argue that where a core cultural value is involved, the costs of challenging that value and seeking to change it are likely to be high in terms of conflict, friction, alienation of organizational constituencies, and impaired effectiveness. They provide examples to "suggest that even a very powerful and culturally indigenous organization may find it more effective to accommodate core cultural values than to challenge them" (Lachman et al., 1994, p. 51). While the Lachman et al. strategies are not directed towards MCS, they are sufficiently generic to provide an informative model for future MCS work.

\section{Simplistic treatment of culture}

Perhaps the major weakness in the studies reviewed for this paper is a tendency to assume an excessive simplicity about the nature of cultural values and dimensions, and to neglect the greater depth, richness and complexity of culture and cultural diversity, which those dimensions cannot capture. Expressed one way, this is the tendency to assume, for example, that "PD is PD is PD", and that theory and empirical results associated with one high PD country are therefore applicable to other high PD nations. Harrison's (1992) framework for studying the cross-cultural generalizability of MCS, developed from his study of participation in Singapore and Australia, is perhaps the most striking example of this simplistic approach. This is exemplified in his conclusion that, because 32 other countries exhibit the high PD/low IDV characteristics of Singapore and 15 the low PD/high IDV characteristics of Australia (as reported by Hofstede, 1980), the "results of research into the effects of participation (in Singapore and Australia) may therefore have widespread application and generalizability crossnationally" (Harrison, 1992, p. 13).

This conclusion is sustainable only on the assumption that the form and nature of PD and IDV, and their implications for MCS, are the same across those 32 and 15 nations. Yet the cross-cultural psychology and sociology literatures provide evidence that this is not the case, with the form and nature of these and other cultural dimensions being quite different among, and even within, societies (Triandis, 1995). The dimensions of PD and IDV are drawn on here to illustrate the diversity and complexity of cultural characteristics across and within societies. PD and IDV are chosen because they have received the strongest 
concordance across value dimensional studies (Schwartz, 1994; Smith et al., 1996).

\subsection{Power distance (PD)}

Lincoln et al. (1981) point out a major difference in the nature of PD in vertical hierarchical relationships in, for example, France compared to Japan (two nations classified in the high PD cluster as scored by Hofstede, 1984, p. 214). They note that while PD manifests in relatively rigid vertical differentiation in social and organizational structures in both societies, the underlying reasons for such manifestation are virtually opposite, leading to contrasting rather than common expectations for related issues such as MCS design. Drawing on Crozier (1964), Lincoln et al. (1981) note that bureaucratic rigidity in France is based on the French distaste for relationships of personal dependency.

Bureaucratic forms in France...are shaped to allow organization under authoritarian administration while elaborate structural barriers (rules, rigid division of labour) shelter employees from personal dependencies (Lincoln et al., 1981, pp. 93-94). ${ }^{5}$

By contrast, drawing on Marsh and Mannari (1976) and Rohlen (1974), Lincoln et al. (1981) describe how an equivalent emphasis on vertical differentiation in Japan is premised on a preference for paternalism and for high levels of dependency and commitment in hierarchical relationships.

While Crozier saw French organizational forms responding to the French need to avoid dependency ties, vertical differentiation in Japanese organizations can be traced directly to a Japanese cultural expectation of relations of precisely this sort (Lincoln et al., 1981, pp. 95-96).

\footnotetext{
5 Triandis, McCusker, Betancourt, Iwao, Leung, Salazar et al. (1993) provide empirical support for the strong rejection of dependence in France in that, of the ten nations they studied, rejection of dependence was strongest in France and was accompanied by an equally strong rejection of sociability.
}

Whitley (1991) also discusses the dependency and mutual trust nature of vertical relationships in Japanese organizations, and allows insight into how the form and nature of power distance varies between Japan and other East Asian, particularly Chinese, societies, where PD translates into a more authoritarian relationship between superior and subordinate.

Japanese managers are not expected to be as remote and aloof from subordinates as are Chinese and Korean ones. A key part of their role is to maintain high morale and performance and they are less directive or didactic than managers in Korean and Chinese firms. These differences in managerial authority are echoed by variations in employment policies and practices which together generate conditional loyalties in Chinese and Korean businesses as opposed to...'emotional' loyalties in Japanese kaisha (Whitley, 1991, p. 3; references in the original quotation are omitted.)

Bond (1991) also elaborates on the paternalistic but more authoritarian relationship between superior and subordinate in Chinese society compared to Japan. Bond (1991, p. 79) notes that Chinese managers:

spend less time consulting in large meetings, reasoning with peers, persuading subordinates, making concessions within the workplace...and...spend more time making decisions alone, giving orders, supervising the execution of those orders personally.

Thus, although the nations illustrated (France, Japan and Chinese-based societies) may be clustered as high PD, and distinguished from an Anglo-American cluster of low PD nations, the variation in the form and nature of power distance in the high PD cluster, at least, means that it is not sufficient to premise MCS studies on an assumed commonality of PD implications for MCS design across these nations. MCS characteristics such as participation, the use of implicit versus explicit controls, and information flows, are all likely to be 
differentially affected by the different forms and nature of PD in these nations.

With respect to information flows for example, Snodgrass and Grant (1986), in their study of the relative emphasis on implicit versus explicit controls in the monitoring, evaluation and reward components of the MCS in companies in Japan and the U.S., noted that the emphasis on the hierarchy is a strength in Japanese firms in that it contributes to more open lines of communication and enhanced information sharing. This occurs because the high degree of vertical differentiation "eliminates the need to hoard information for one's own career or advancement. Because everyone knows what their personal interdependencies are (as defined by the hierarchy), information can be shared" (Snodgrass \& Grant, 1986, p. 214). Added to this is the trust relationship which maintains between hierarchical levels in Japanese organizations (Snodgrass \& Grant, 1986, p. 215; Whitley, 1991, p. 3). Snodgrass and Grant (1986, p. 215) argue, that because of the trust and personal interdependence that underscores the hierarchy, the hierarchy is "probably the strongest control mechanism in these (Japanese) companies".

By contrast, the hierarchy may be seen as an obstacle to the free flow and open exchange of information in Chinese-based organizations. Bond (1991, p. 83) argues this way when noting the more authoritarian and distanced nature of relationships in Chinese hierarchies.

Subordinates are less likely to volunteer opinions, take individual initiative, or depart from standard operating procedures without a superior's approval. For the consequences of making a mistake will devolve upon the subordinate and there will be little institutional protection against the superior's wrath (Bond, 1991, p. 83).

This authoritarian and distanced relationship, combined with loyalties which Bond notes are "only as wide as the immediate boss's range of relationships...and hence...difficult to meld into an organization-wide affiliation...often results in inter-departmental indifference, stonewalling, and competitiveness in Chinese organizations" (Bond, 1991, p. 84).
The foregoing examples which demonstrate the substantially different (indeed, opposite) effects on MCS characteristics arising from differences in the form and nature of PD in nations otherwise classified in aggregate as high PD, also demonstrate the need for future studies to draw more deeply on the literatures that allow a richer, more complex understanding of the cultures of specific societies. It is salutary to note that the examples given (Lincoln et al., 1981; Snodgrass \& Grant, 1986) are both early studies in the research reviewed and did not draw on Hofstede's (1980) dimensions. Rather, they drew on in-depth sociological and anthropological works on the specific countries and cultures at issue (Crozier's (1964), sociologybased treatise on French bureaucracy and Rohlen's (1974) anthropological study of Japanese "white-collar" organizations). As such, they were informed by a deeper understanding of the complexity and diversity of culture in the nations at issue than were the later studies in the review. These later studies have tended to seize upon Hofstede's aggregated and clustered dimensions, and, as a result, have glossed over important differences and nuances in culture and drawn inappropriate and simplistic conclusions.

\subsection{Individualism/collectivism (IDV)}

The failure to recognize or capture the complexity and diversity of culture in much of the crosscultural MCS research is evident also in the treatment of Individualism/Collectivism (IDV). Developing in parallel with the MCS research is a substantial body of research into individualism and collectivism in the psychology literature, the results of which suggest a number of important considerations in the examination of IDV in cross-cultural MCS research. Two of these are (i) the complex factor structure of collectivism and the variation in that structure among nations which may, in more aggregate terms, be classified as collectivist, and (ii) the focus of collectivism in terms of the definition of the ingroup.

\subsubsection{Factor structure of collectivism}

Triandis (1995) notes that there are a large number of different types of collectivism and 
individualism. With respect to individualism, he (1995, pp. 45-46, 95-99) provides examples of differences between Swedish, North American, Australian, British, German and French individualism. With respect to collectivism, Triandis et al. (1993, p. 377) argue, and demonstrate through their study of 1614 people in ten countries, that "cultures are not 'monolithically collectivist' but that there is substantial complexity in their tendencies towards collectivism". Their findings for Indonesia illustrate their argument. While they found that Indonesia shared values of a strong rejection of separation from the group with some other collectivist nations, and a strong emphasis on sociability with others, they also found a number of "collectivist" factors which emerged uniquely for Indonesia (including affiliation without competition), and which therefore distinguished the form and structure of Indonesian collectivism from that of other equally strong collectivist societies.

Triandis $(1989,1995)$ also invokes Pelto's (1968) distinction between tight and loose (or homogeneous and heterogeneous) cultures as an important consideration in assessing effects of collectivism. Tight cultures are ones in which "norms and values of ingroups are similar (and which are) rigid in requiring that ingroup members behave according to the ingroup norms"; by contrast "heterogeneous societies have groups with dissimilar norms (and) are flexible in dealing with ingroup members who deviate from group norms" (Triandis, 1989, p. 511). Triandis (1989) argues that there is considerable variation in the degree of "tightness" or "looseness" within collectivist nations.

This point allows potential explanation for some of the disparity in prior cross-cultural MCS research. For example, Triandis (1989, 1995) determined that Japan constituted a tight collectivist culture, while Thailand, China and India were relatively loose, with Thailand being singled out as a particularly loose collectivist culture. This is consistent with, and may explain, the findings of Vance et al. (1992) in their study of performance evaluation systems in Thailand, Malaysia and Indonesia that the Thais seemed to be more individualistic than collectivist when compared to the other two East Asian nations. In explaining the looseness of Thai collectivism, Triandis (1989, p. 511) highlights Thailand's "marginal position between the major cultures of India and China" with the result that Thai "people are pulled in different directions by sometimes contrasting norms, and hence they must be more flexible in imposing their norms". Added to this, Vance et al. (1992, p. 322) noted the widespread influence of Theravada Buddhism in Thailand which stresses tolerance for individual diversity and initiative. Thus, the findings of Vance et al., which may be seen as anomalous from an assumption of commonality and uniformity of collectivism, are explicable with recognition of the diversity of the dimension's factor structure. ${ }^{6}$

\subsubsection{Focus of collectivism}

There is a tendency in the cross-cultural MCS research to assume that collectivist nations prefer group situations over individual ones, with a variety of prognoses for, inter alia, participation (Harrison, 1992; Lau et al., 1995; Chow et al., 1996a), decision making processes (Harrison et al., 1994), and incentive schemes (Chow et al., 1991; Chow et al., 1994; Merchant et al., 1995); and that such preferences are driven by a collectivist orientation to the group situation generically and absolutely. However, there is now considerable evidence that the assumption of a generic orientation to group situations is invalid. In this respect, Kagitcibasi and Berry (1989) point out that who the group is makes a critical difference. They, along with many other writers in this area such as Earley (1993), Triandis (1989) and Bond (1991), distinguish between ingroups and outgroups, and contend that subjects from collectivist cultures exhibit the behavioural characteristics typically

\footnotetext{
${ }^{6}$ An additional complexity is the assumption that individualism/collectivism is unidimensional. While Hofstede's scoring of countries on this dimension suggests unidimensionality, and MCS studies have tended to assume accordingly, the psychology literature suggests otherwise. Kagitcibasi and Berry (1989) show that individualism and collectivism are not mutually exclusive. Similarly Bochner (1994), in his study of Malaysian (collectivist) and Australian and British (individualist) subjects, found that all three subject samples had more idiocentric than group self-descriptions, although the ratio of group to idiocentric statements was significantly higher in Malaysia compared to the two individualist cultures.
} 
associated with collectivism only with members of the in-group; by contrast, "with out-group members their behaviour resembles that of subjects from individualistic cultures" (Kagitcibasi \& Berry, 1989, p. 517).

Triandis (1988, pp. 74-75) defines an ingroup as a group whose members share many common interests and traits and are concerned about each other's welfare, with Kagitcibasi and Berry (1989) and Triandis (1988) both demonstrating how the meaning and membership of ingroups (and outgroups) vary across collectivist cultures. Whitley (1991), in his study of the social construction of business systems in East Asia which contrasts the Japanese kaisha, the Korean chaebol, and the Chinese family business, makes the distinction that the collectivist orientation of the Japanese is towards the organization, and that of the Chinese towards the family. ${ }^{7}$ Thus, while the focus of collectivism in Japan might be relatively closely aligned with the organization, with the sharing of interests at corporate level resulting in the observed commitment to the organization of most employees therein (Whitley, 1991), the situation is different in Chinese nations where the corporation is likely to comprise multiple ingroups and outgroups aligned with more restricted workgroups within the corporation. This latter situation gives rise to a number of observed behaviours in corporations in Chinese collectivist cultures which are not normally or generically associated with collectivism. ${ }^{8}$

The distinction between ingroups and outgroups has not been clearly recognized or addressed in the MCS research employing the

\footnotetext{
7 This distinction was also pointed out by one of the authors' postgraduate students through the analogy that Japanese collectivism is a "block of granite" (Fukuyama, 1995, Ch. 14), while Chinese collectivism is a "tray of sand", with each grain representing a family. By contrast with both Japanese and Chinese society, the focus of collectivism in Indonesia is the community. Termed pancasila, Indonesia's community based collectivism is founded on a set of five basic principles, which are embedded in the Constitution and are inculcated through the education system. The principles are belief in God, civilized humanity, unity, consultation to reach consensus, and social justice. Gotong royong (mutual assistance) is a main value in pancasila, which brings together the multi-ethnic and religious groups that comprise Indonesia.
}

collectivism dimension, and may account for some of the disparity or absence of findings. Chow et al. (1991), for example, hypothesized that people from individualist cultures would perform better under workflow and pay independence (i.e. independence from groups and others), and people from collectivist cultures would perform best under workflow and pay interdependence (with groups and others). Their results, obtained from an experiment within which Singaporean and U.S. university students undertook a task of translating triplets of numbers into alphabetic letters via a translation code, showed no, or only limited support for their interactive culture hypotheses. The failure to find the hypothesized effect may well be attributable to the failure of their experimental manipulation to establish the ingroup/outgroup relationship with sufficient reality and intensity to activate the presumed collective behaviours. Chow et al. (1991, p. 215) note:

Cultural individualism was controlled experimentally by obtaining half of the sample from Singapore and the other half from the U.S.A. This manipulation was empirically successful, as the U.S. subjects measured significantly higher in individualism.

This statement assumes that the act of assigning people (in this instance, students) from collectivist cultures to a generic group situation is sufficient to activate group oriented behaviour. However, although the Singapore sample might have recorded more "collectivist" scores than the U.S. sample on a pencil and paper IDV measure, it is unlikely that the act of group assignment alone was sufficient to simulate the specific interpersonal relationships and interdependency characteristic

\footnotetext{
${ }^{8}$ Examples of such observed behaviours among members of the same corporation but of different outgroups within the corporation include poor communication (Triandis, 1967), counterproductive competitiveness, hostility and lack of trust (Triandis, 1989, p. 516). Additionally, Earley (1993), in an experiment involving collectivist and individualist subjects, found that the individualists performed better alone than in a group, and the collectivists performed best in a group situation, but only where the group was an ingroup. Collectivists performed better alone than in an outgroup.
} 
of ingroups, which are, in turn, necessary to stimulate the group oriented behaviours on which the Chow et al. (1991) theory rested. By contrast, Earley (1993), in his study of group vs individual performance between collectivists and individualists, went to considerable effort in his experimental realizations to create the ingroup/outgroup status, and to establish perceptions of shared characteristics among ingroup members, including kinship, friendship and religious backgrounds, as well as general interests and lifestyles.

The different foci of collectivism is also relevant as a potential explanator of the results of other MCS studies including Vance et al. (1992) and Merchant et al. (1995). The variable and partially inconsistent results of Vance et al. (1992) among the three "collectivist" societies of Thailand, Malaysia and Indonesia may well be a reflection not only of the relative tightness and looseness of collectivism in those societies (as discussed in the previous section), but also of the different focus of collectivism. (See Footnote 7 for how the nature of collectivism in Indonesia contrasts with other Asian nations.) Similarly, Merchant et al. (1995) developed and tested several hypotheses about performance evaluation systems in the U.S. and Taiwan, part of the theory for which rested on the assumption that, as Taiwan was a collectivist nation, there would be a culturally-driven orientation of Taiwanese managers to the firm, i.e. that the focus of collectivism in Taiwan is the firm. That their results were largely inconsistent with their hypotheses may well be attributable to the question of whether this assumption is valid or whether, as noted earlier, the focus of collectivism in Chinese based organizations is aligned not with the organization as a whole, but with more restricted subgroups within the organization, with consequences for competitive, rather than cooperative, behaviour among organizational subgroups.

The Merchant et al. (1995) study highlights the need for a better understanding of the nature and functioning of ingroups and outgroups in modern Chinese organizations. We know little about MCSrelated situations in which the ingroup/outgroup conflict is important (and where it is not), and how the presence of other characteristics of Chinese cul- ture, such as respect for hierarchical relations, concern with face, and a sense of duty and loyalty, affect the balance between a concern with ingroup and a concern with company in different MCS contexts.

As for the conclusion of the earlier discussion of $\mathrm{PD}$, the reason that we know little about the implications of the ingroup/outgroup distinction for MCS, and that the cross-cultural MCS research has not recognized or accommodated the complexity of collectivism, again appears to result from an unquestioned and uncritical reliance on Hofstede's aggregate cultural dimensions. The consequence of this reliance has been a corresponding neglect of the richer and more indepth understandings of individualism/collectivism (and of culture generally) available in works dedicated to describing and analysing the cultures of individual societies. It is to these literatures that future cross-cultural MCS research must turn if it is to overcome the present simplicity in its treatment of culture.

\section{Restricted conception of culture}

The foregoing sections of the paper have identified a number of deficiencies with the way in which the cross-cultural MCS research to date has operationalized the treatment of culture within a conception of culture that is based on norms and values. Additionally, the paper has sought to discuss ways in which future research can be improved within this conceptualization. However, as noted at the outset, the restriction of the existing research to this conception of culture is itself a weakness, and one which places critical limits on the extent of understanding that can be derived from such research.

By conceptualizing culture through the functionalist lens of values alone, the research fails to recognize that values are only one aspect of culture (Triandis, 1993), and only one way of conceiving of culture (Wuthnow, Hunter, Bergesen \& Kurzweil, 1984; Agger, 1992). As a consequence, the research fails to benefit from other, post-functionalist conceptions in sociology, anthropology and history. The limitations on perspective 
imposed by the value lens are summarised by Alexander and Smith (1993) as; (i) failing to recognize the "complexity and contingency of human action" (p. 151), and (ii) failing to explain the "characteristics and dynamics of specific groups, organizations, and subsystems in concrete social settings" (p. 155).

The first of these limitations is seen by Alexander and Smith (1993, p. 155) to derive from the fact that values are analytical constructs, typically developed from observed behaviour, and, as such, do not address "the concrete thoughts, feelings and emotive responses of members of a lifeworld". They argue, also, that while values comprise meaning, they "pitch meaning at a very generalized level under umbrella-like concepts (and, hence, fail to provide) a detailed picture of the internal workings of the cultural environment" (Alexander \& Smith, 1993, p. 155). In similar vein, Alexander and Seidman (1990, p. 6) argue that the functionalist value lens does not capture symbolic phenomena such as ritual, myth, narrative, metaphor, language and code. The second limitation is seen to derive from the perspective of the value lens on shared (i.e. agreed upon) meaning, with implications for the presumption of consensus in societal existence which typified functionalism (Giddens, 1993, p. 721). Such a premise was seen to conceal from this lens social structural considerations (of power and economic resource distribution, for example), and the conflicts and tensions arising from asymmetries and differentials therein, which underscore the conceptions of culture in institution and class based theories (Alexander \& Smith, 1993, p. 155; Giddens, 1993, p. 721).

In response to the limitations on the value lens perspective, post-functionalist approaches have emphasised actor-centred and/or social structural understandings of culture. These perspectives, and the social philosophies underlying them, are multiple, diverse and contested in their base disciplines. Van Maanen (1988, p. 10) notes that: "In anthropology, for example, pitched battles are fought on this issue (of what constitutes an adequate cultural description and understanding)... and similar controversies rage across several sociologies". Theoretical exploration of the multi- ple perspectives and their contestation is beyond the scope and purpose of this paper. However, of great relevance to the paper is the contribution that such perspectives can make in removing the narrowness of scope imposed by the concentration of existing cross-cultural MCS research on value lens models. To this end, in the remainder of the paper we draw attention to examples of such perspectives and some instances of applications which may help guide future cross-cultural MCS research.

One such perspective is that of Thompson (1990), who conceives of culture as symbolic forms in structured contexts and describes cultural analysis as:

the study of symbolic forms - that is, meaningful actions, objects and expressions of various kinds - in relation to the historically specific and socially structured contexts and processes within which, and by means of which, these symbolic forms are produced, transmitted and received (Thompson, 1990, p. 136).

Thompson gives the example of a speech which cannot be understood in terms of its structural features and systemic elements, but only by attending to contextual aspects such as the setting and occasion of the speech, the relations between the speaker and the audience, and the media of transmission. These aspects "can be discerned only by attending to the social contexts, institutions and processes within which the speech is uttered, transmitted and received and by analysing the relations of power, forms of authority, kinds of resources and other characteristics of these contexts" (Thompson, 1990, p. 145).

Similar conceptualizations of culture are contained in the work of Giddens (1987) and Alexander and Smith (1993). Giddens (1987) argues that a theory of culture must be built upon a basis of human agency, which, in turn, must be explicated in terms of practical consciousness (the process whereby humans "reflexively monitor what they do as an intrinsic part of what it is that they do") and the contextuality of action ("settings of action, whose qualities agents routinely 
draw upon in the course of orienting what they do and what they say to one another") (Giddens, 1987, p. 215). Alexander and Smith (1993, p. 16) conceive of culture as "a system of symbolic codes which specify the good and the evil", and argue through illustration how symbolic codes are implicated in individual action through both their internalization in informing action and their external accountability for action. $^{9}$

These conceptualizations of culture provide opportunities for cross-cultural MCS research to break off the shackles of its hitherto reliance on the value lens perspective, and to open up new areas of understanding. First, they allow opportunities for such research to move beyond its existing static nature, which constrain it to establishing (or not establishing) point-in-time statistical associations between values as independent variables and affective and/or behavioural responses as dependent ones. With the variables remote and unanchored in time and context and their temporal and spatial dependencies unexplored, and with associations among the variables premised on assertedly deterministic and equally unexplored meanings, such research cannot explore the dynamics and processes of MCS and their cultural interplays, cannot get at the cultural meaning and significance constituted in actions in MCS settings, and cannot appreciate the spatial and temporal/ historical context of those processes and actions.

\footnotetext{
${ }^{9}$ While not seeking to constrain researchers in their choice of the multiple perspectives offered in the contemporary sociology, anthropology and history literatures, these perspectives are chosen here because they appear to overcome some of the criticisms of other perspectives. For example, Thompson (1990), while stating his regard for Geertz's symbolic/semiotic work as the most important formulation of culture in the anthropology literature, provides several criticisms of this work including its inadequate attention to the structured social relations (including those of power and conflict) within which symbols and symbolic actions are embedded. Thus, Thompson follows Geertz's symbolic interpretational conception of culture, wherein symbols and symbolic forms are the active expressions of agents, but adds to it the spatio-temporal context in which symbols and symbolic forms are embedded. Similarly, Alexander and Smith (1993) criticise the actorcentred and social structural conceptions generally for their inability to attend to issues of meaning.
}

An example relates to the understanding of participation in MCS contexts. Existing cross-cultural MCS research generally corroborates an association between culture (operationalized through measurement of the power distance and individualism/collectivism value dimensions) and participation (measured using the Milani (1975) six-item pencil and paper self-report instrument) (Harrison, 1992; O’Connor, 1995; Lau et al., 1995). However, with (and despite) the exception of the insight into the involvement and influence sub-dimensions of participation in O'Connor's (1995) findings, these studies and their constraining methods reveal nothing about the various forms participation may take in different societies, the various purposes participation may serve, or the dynamics of the process whereby participation takes place, including both the vehicles and mechanisms it may use and the roles of differentiated actors in the participation process. Nor can these studies gain understandings of the specific meanings, motives and significations attributed to participation by organizational members, or of the historical and social structural contexts within which such meanings, motives and significations are formed and embedded.

While not concerned with participation per se, Nussbaum-Gomes' (1994) ethnographic study of control in the Japanese organization Mitsubishi Heavy Industries provides an example of how the foregoing conceptions of culture and their associated methodologies can benefit MCS research. As part of her study, Nussbaum-Gomes examines the phenomenon of informal group socializing among Japanese employees after hours and in the organized "works outings" and special parties. While participation in such activities is espoused as voluntary on an individual basis, the tendency is that everyone always goes. A value driven explanation for this behaviour might draw on the maintenance of shared values of collectivism, group (organizational) consciousness and cohesiveness, and harmony. While probably containing some partial contribution to explanation, such an explanation would nonetheless be facile.

Nussbaum-Gomes uses ethnographic techniques to seek out the individuals' articulation and 
meaning of these informal and organized social activities, and demonstrates that employees interpret and construct them not as voluntary but as obligatory, and participate not as an intrinsic, unreflexive, manifestation of shared values, but because of a conscious and knowledgeable choice of self-interested action. Specifically, NussbaumGomes describes a situation where the values of cohesiveness and harmony are not uncontested among individuals, but where those values are primary criteria for manager evaluation and promotion and are known to be such, with the consequences that social activities become symbolic representations of organizationally valued behaviours. The conscious choice on the part of individuals to participate in them arises, paradoxically, from their perceived absence of choice, with failure to participate having real consequences in adverse effects on evaluation, reward and promotion.

This example is used not only to demonstrate the importance of getting at the meanings individuals attribute to actions and choices, and the specific structures, including power differentials, surrounding those actions, (rather than leaving the meaning link unexplored and unexplained except in value-assertive terms); the example also demonstrates the revelations and discoveries that are possible through the approach NussbaumGomes employs. Of particular relevance to the study of participation here is the finding that the informal after-hours socializing and work outings are forums for information exchange among organizational members at all levels, and for keeping individuals informed of, and involved in organizational decisions. In their articulation of what the socializing and outings meant to them, employees described a situation where, if they did not attend, they would not know what was going on in the organization and their absence would be noted and talked about. Thus, Japanese management may be seen to construct the socializing and outings, and the attendant climate surrounding them, such that they play an important role both in promoting information sharing among organizational members, and in ensuring employees are informed about, and become acceptive of, management decisions. Such forums, therefore, constitute in the organization concerned, and potentially more widely in Japanese organizations, a significant vehicle of participation, but one which would not have been visible through the value perspective and the methods employed in the cross-cultural MCS research to date. ${ }^{10}$

A second example relates to understanding how management control systems are constituted holistically in different societies and how they operate in terms of their processual dynamics. Chow et al. (1994) pointed out that, contrary to most of the cross-cultural MCS research to that time (and since) which treated both national culture and MCS as comprised of separate and independent dimensions or component parts, both culture and MCS are holisms, with MCS existing as packages of mechanisms and processes which are in simultaneous dynamic operation, and which may serve as substitutes or complements for one another. Based on the presumption that such packages and processes might differ cross-nationally, and drawing on cultural value dimensions, Chow et al. (1994) examined, through laboratory experiments involving Japanese and U.S. MBA students, whether the preference sets among eleven MCS characteristics differed between the Japanese and U.S. subjects. While they did find different preferences and trade-offs among preferences between the samples, they were unable to disentangle and explain the link between the cultural dimensions and these compensatory trade-offs.

This interpretation failing could support an argument for more studies using the value conceptualization of culture and the cross-sectional analytical methodologies typical of the existing

\footnotetext{
${ }^{10}$ As a reviewer for the paper pointed out, the NussbaumGomes study does not answer the question of whether the Japanese companies construct the social activities to serve the purposes of participation and information exchange, or whether the (corporate) values lead to the existence of the social activities generically with a consequence that the purposes identified are subsequently served therein. At a general level, this comment suggests that neither the values perspective, which assumes a linear dominance of values over behaviour, nor the alternative perspectives, which deny this linearity and dominance, may be sufficient in explanation. Rather, explanation may need recognition of the greater complexity and potential reciprocity of the interrelationship among collective values, and individual actions and choices.
} 
cross-cultural MCS research, as part of the reason for the failure was the lack of theoretical or empirical work on some MCS characteristics. However, an alternative argument is that the attempt to articulate an holistic conception of MCS through a value driven conceptualization of culture and its attendant methodologies not only places unmanageable demands on the interpretational capabilities of cross-sectional methods and statistical analyses, but also misses the essence of MCS holism that Chow et al. (1994) correctly identified, as well as missing the processual dynamism and complexity of MCS.

Understanding the contemporary state of an holistic MCS, where state does not imply stasis but rather the processes and interactions among actors and structures that constitute the dynamic and complex life of the whole, is possible through the interpretational perspectives and methodologies of anthropology, sociology, and history. Janelli (1993) is a good example of how an anthropologist using ethnographic methods of participant observation and interviews and drawing on narrative and history, can produce a rich and complex description and analysis of the dynamics of life and work among white-collar workers and managers in a South Korean conglomerate. Van Maanen's (1988) ethnographic study of police culture, again based on participant observation and using narrative and stories, is similarly insightful.

The emphasis on narrative and history in these examples is integral to understanding the dynamic functioning of contemporary MCS in different societies (and of broader systems such as the organization of Janelli (1993), or of narrower ones such as budget processes within MCS), and how that functioning reflects and carries culture. Narrative and stories are emphasised because of their importance in conveying how people in the organization see and interpret how they fit into the social structural context: "In talk, the agent and the setting are the means whereby culture is linked to communication" (Giddens, 1987, p. 217). Shearing and Ericson (1991) provide an operational example in their study of police culture. They conceive of culture as figurative action and discuss, and rely on, the importance of stories in communicating and understanding culture.

Stories and the tropes that drive them, provide a very different sort of 'generative program' from that envisioned when such programs are rule guided. This conception does not conceive of people as 'cultural dopes' (Shearing \& Ericson, 1991, pp. 499$500)$.

History is emphasised because of its importance in understanding how a specific phenomenon (the MCS for example) has reached its contemporary state, particularly via the cultural, economic, and social structural backgrounds that have led to that state. Emirbayer and Goodwin (1994, p. 1411), in their assessment of network theory in sociological research, conclude that "only a strategy for historical explanation that synthesizes social structural and cultural analysis can adequately explain the formation, reproduction, and transformation of (as their particular phenomenon of interest) networks themselves". They point out the importance of culture and cultural structures in historical context and analysis for understanding how actors are enabled and constrained in social action. By way of illustration, Abelmann (1996) cites several examples of anthropological studies which have incorporated such historical analysis, including Kondo's (1990) ethnographic study of a Japanese factory wherein "culturally, historic specific pathways" were seen to offer insight and explanation into present phenomena. Similarly, Janelli's (1993) study, noted earlier, also uses Korean political, economic and social history to inform his description of life in the Korean conglomerate.

Perspectives and methodologies from sociology, anthropology and history, such as those described and exemplified in this section of the paper, have informed studies of organizations and organizational cultures for some time (see the December 1979 and September 1983 special issues of Administrative Science Quarterly on Qualitative Methodology and Organizational Culture, respectively, and subsequent issues for examples of such work), as well as being called on in a variety of accounting research contexts (a review of the contents of 
Accounting, Organizations and Society over the last two decades will yield examples of theoretical and empirical work in this vein). However, such perspectives and methodologies have not, to date, informed cross-cultural MCS research, where they have much to offer.

\section{Conclusions and suggestions for future research}

As we noted at the outset, cross-cultural MCS research is still in its infancy. While it has progressed beyond its atheoretical stage to one where most studies now consider culture explicitly, our review suggests that we may have reached another turning point at which we must reconsider the way in which we approach culture in MCS research. The research to date has been informed almost exclusively by the value dimensional conception of culture typical of the cross-cultural psychology literature, and even more narrowly within that conception, has relied almost totally on Hofstede's value dimensions. While such reliance has advanced our ability to conduct theoretically driven cross-cultural studies, it has also allowed us to become lazy. Even within the value dimensional conception, our review identified three major weaknesses in the studies to date. First, we observed a tendency to be selective among the cultural dimensions relied on in many studies with a consequent failure to consider, theoretically and/ or methodologically, the totality of the cultural domain as it may impact on MCS. Second, we observed an almost universal tendency to treat the dimensions as if they were equally important across nations, with a corresponding failure to consider the more complex issue of the differential centrality or intensity of cultural norms and values across societies. And third, we observed the tendency to treat the value dimensions superficially through assuming a uniformity and unidimensionality for each dimension that is neither sustainable nor valid.

Concentration on the value dimensional conception of culture, and the concomitant crosssectional methodology of variable relationships, has also meant that the MCS research to date has ignored other conceptions and perspectives on culture, and their associated methodologies, emerging from the anthropology, sociology, and history literatures. As such, the research has been highly restricted in focus, and limited in its ability to examine and understand the dynamic processes of MCS and their cultural interplays, the cultural meaning and significance constituted in the actions of actors in MCS processes, and the spatial and temporal contexts of those processes and actions.

For those who choose to work within the value dimensional conception, much remains to be done. For example, as noted earlier, there has been little overlap in the MCS characteristics studied to date, and, where overlap exists, typically the methods of operationalizing the characteristics have been sufficiently different to make comparisons difficult. The research to date has, literally, "grown like Topsy" (a bit here and a bit there), with no underlying systematic pattern and, hence, with little cumulative addition to our knowledge base. Even those authors who have concentrated their efforts in this area, and who have contributed multiple studies to the literature, tend not to have developed their studies sequentially, but rather to have jumped from one MCS characteristic to the next. While this tendency may be driven by a perception of lack of peer acceptance of replication or corroborative work, it seems clear that such work is needed in future research in the cross-cultural MCS area.

A number of other avenues for fruitful future research have emerged from our review, our discussions with colleagues in this area of study, and particularly from the insightful comments of the anonymous reviewers for this paper. These suggestions, while acknowledging in general terms that replication work is needed, require that future work targeting previously studied or new issues must ensure organizational and managerial relevance in the constantly changing technological and competitive environment of the late 20th and 21 st centuries, and also needs to recognize (and examine) culture's interdependencies with other important variables, as well as the culture-MCS interdependency itself.

Taking this latter consideration first, the majority of the extant research has assumed that culture 
(comprising one or more of a set of component dimensions) exists, and affects or interacts with MCS, in isolation from or independent of other variables or circumstances, including economic variables of competition and markets, for example, and technological, regulatory and political circumstances. On the one hand, this is a limitation of the existing research, with the omission of such variables and circumstances, and the neglect of their effect on the culture-control relation, substantially circumscribing the research's potential to explain control characteristics. On the other hand, it points to two important opportunities for future research to include such variables along with culture. An important theoretical issue for future research is whether and how such non-cultural variables interact (either in moderating or intervening form) with culture in the culture-control relation. An important empirical issue is the relative importance of cultural and non-cultural variables in explaining control phenomena, independently and/or in interaction. A further related avenue for future research lies in the recognition of the interdependency between culture and control in terms of their joint ability to affect outcome variables. This would overcome the present restriction of focus on the association between culture and control, and allow examination of more complete, multiple contingency relationships.

With respect to outcome variables, future research should also target culture's interplay with those characteristics of organizational functioning which are seen as increasingly necessary for success in the contemporary business environment, with its characteristics of unprecedented levels of technological change, product and service innovation, and intense global competition. Within this environment, some of the "traditional" variables studied in much of the extant cross-cultural MCS literature may be dated. Although opinions will differ, we suggest that future research will be more contemporarily relevant and productive if directed less at issues such as vertical and horizontal differentiation, formalization, responsibility centre format, participation, and budget emphasis in evaluative style, for example, (issues which are themselves becoming less important in the general management and control literatures, or are at least assuming different forms), and more towards those operational capabilities needed to attain and sustain organizational learning, adaptive flexibility and innovation. In this latter context, future research can usefully address the interplay between culture and issues such as information and experience sharing behaviours within organizations, risk taking and innovative propensities, and the development and maintenance of flexible organization structures and interaction patterns, such as the use of fluid workgroups and teams.

Other suggestions for future research have been noted in the paper. At the specific level, these include research into the nature and functioning of ingroups and outgroups in modern Chinese organizations, and how such group interrelationships affect MCS and organizational characteristics such as, for example, information sharing. At the general level is the potentially very fruitful question of the relation between national and organizational cultures, and whether organizations operating internationally must accept uncritically the national cultural dictates of their overseas host countries, or whether through time and selection and socialization practices those organizations can modify national cultural influences within their overseas units through the creation of cultural microclimates. As noted earlier, only two studies have examined this issue and have produced contrasting results. Further work has the potential to forge a coherent research agenda in this important area.

Future studies using the value dimensional lens are, therefore, clearly warranted. However, such studies need to become more precise in their theoretical understanding and methodological operationalization of culture, and to address the greater complexity and diversity of culture than has typified research relying on Hofstede. Such studies need to recognize and accommodate in their theory the centrality of values, perhaps using the instructive core versus peripheral values approach (an approach particularly pertinent to the national vs organizational culture issue noted in the paragraph above), and the finer partitioning of culture and cultural dimensions, as evidenced in the analysis of power distance and individualism/ 
collectivism previously in the paper. To do this it will be necessary to go beyond Hofstede's scores and ranks and draw more deeply on the richer social and cultural literatures and commentaries for the specific nation(s) concerned.

Transcending Hofstede's scores and ranks will also allow future research to address concerns about the contemporary relevance of those scores and ranks generated nearly 30 years ago. While cultures, by definition, change only slowly, and Hofstede's measures have received more recent support (Smith et al., 1996, for example), the rapidity and intensity of globalization in contemporary times has the potential to reduce some cultural differences across societies, particularly with generational change. Which cultural differences may maintain and which may be reduced through such global exchange and generational change is a question meritorious of study in its own right, and one which, again, would usefully be guided by the core versus peripheral values conceptualization.

A final methodological caution on the past and future research relates to method. It was noted earlier that the predominant, almost exclusive, method employed to date has been the mail survey questionnaire. It is unusual in research generally for exploratory work to be conducted using the survey method. Typically, this method is invoked later in the development of a research area as relationships among variables and phenomena at issue are better understood through field or experimental methods. While the mail survey questionnaire has allowed cost efficiencies in the conduct of cross-cultural MCS research, we may have paid a price in its having yielded a lower level of understanding of the phenomena than we might have obtained with other methods or, at least, with multiple methods.

The time and cost constraints of full ethnographic studies probably mean that such methods are not available to all, indeed even many, researchers. For those who choose to look beyond the value dimensional lens on culture, and this is the only way in which the research can transcend its present limitations of scope and focus, the ethnographic methods and the conceptualizations of culture in the anthropology, sociology, and history literatures are probably necessary and offer promising opportunities. Even for those for whom such methods are unattainable, however, it must be recognized that continued reliance on mail survey questionnaires alone will continue to restrict understanding and meaning. A potential resolution to this dilemma is the use of field based surveys (a term usefully provided by one of the reviewers of this paper), whereby the researcher visits and gains insight into the context of the research site(s) before administering and interpreting the data from his/her questionnaire. A questionnaire administered in this context might usefully include, in addition to closed-ended, quantitative-based questions, open-ended questions which allow the researcher to explore through discussion the complexities and interrelations that underlie the respondent's answers to the quantitative questions. This approach, which offers the advantages of lower costs than full ethnographic studies and greater contextual understanding than mail surveys, may well be an effective methodological step forward in crosscultural MCS research.

\section{Acknowledgements}

The authors wish to acknowledge the helpful comments of Anthony Hopwood, two anonymous reviewers, participants at the AOS Conference on Comparative Management Accounting, University of Siena, November 1996, and participants in the research seminar series at Warwick University Business School, the University of Adelaide, and Macquarie University.

\section{References}

Abelmann, N. (1996). Reviews of "culture" and capitalism in South Korea. Reviews in Anthropology, 25, 185-194.

Agger, B. (1992). Cultural studies as critical theory. London: The Falmer Press.

Alexander, J. C., \& Seidman, S. (1990). Culture and society: contemporary debates. Cambridge: Cambridge University Press. Alexander, J. C., \& Smith, P. (1993) The discourse of American civil society: a new proposal for cultural studies. Theory and Society, 22, 151-207. 
Bhagat, R. S., \& McQuaid, S. J. (1983). Role of subjective culture in organizations: a review and directions for future research. Journal of Applied Psychology, 68, 653-695.

Birnbaum, P. H., \& Wong, G. Y. Y. (1985). Organizational structure of multinational banks in Hong Kong from a culture-free perspective. Administrative Science Quarterly, 30, 262-277.

Birnberg, J. G., \& Snodgrass, C. (1988). Culture and control: A field study. Accounting, Organizations and Society, 13, 447-464.

Bochner, S. (1994). Cross-cultural differences in the self concept: a test of Hofstede's individualism/collectivism distinction. Journal of Cross-Cultural Psychology, 25, 273-283.

Bond, M. H. (1991). Beyond the Chinese face: insights from psychology. Oxford: Oxford University Press.

Bosland, N. (1984). Some studies on the value survey module. Unpublished M.A. thesis, Catholic University, Tilburg, The Netherlands.

Brownell, P. (1982). The role of accounting data in performance evaluation, budgetary participation, and organizational effectiveness. Journal of Accounting Research, 20, 12-27.

Child, J. (1981). Culture, contingency and capitalism in the cross-national study of organizations. In L. L. Cummings \& B. M. Staw (Eds), Research in Organizational Behavior (pp. 303-356). Greenwich, CT: JAI Press.

Chiu, J. S., \& Chang, D. L. (1979). Management accounting in Taiwan. Management Accounting, 60, 50-55.

Chow, C. W., Shields, M. D., \& Chan, Y. K. (1991). The effects of management controls and national culture on manufacturing performance: an experimental investigation. Accounting, Organizations and Society, 16, 209-226.

Chow, C. W., Kato, Y., \& Shields, M. D. (1994). National culture and the preference for management controls: an exploratory study of the firm-labor market interface. Accounting, Organizations and Society, 19, 381-400.

Chow, C. W., Shields, M. D., \& Wu, A. (1996a, November). The importance of national culture in the design of and preference for management controls for multinational operations. Paper presented at the Accounting, Organizations and Society Comparative Management Accounting Conference, University of Siena, Italy.

Chow, C. W., Kato, Y., \& Merchant, K. A. (1996b). The use of organizational controls and their effects on data manipulation and management myopia: a Japan vs U.S. comparison. Accounting, Organizations and Society, 21, 175-192.

Cragin, J. P. (1986). Management technology absorption in China. In S. R. Clegg, D. C. Dunphy \& S. G. Redding (Eds.), The enterprise and management in East Asia. Hong Kong: Centre of Asian Studies of Hong Kong.

Crozier, M. (1964). The bureaucratic phenomenon. Chicago: University of Chicago Press.

Daley, L., Jiambalvo, J., Sundem, G. L., \& Kondo, Y. (1985). Attitudes toward financial control systems in the United States and Japan. Journal of International Business Studies, Fall, 91-110.

Earley, P. C. (1993). East meets west meets mideast: further explorations of collectivistic and individualistic work groups. Academy of Management Journal, 36, 319-348.
Emirbayer, M., \& Goodwin, J. (1994). Network analysis, culture, and the problem of agency. American Journal of Sociology, 99, 1411-1454.

French, J., Israel, J., \& As, D. (1960). An experiment on participation in a Norwegian factory. Human Relations, 13, 3-20.

Frucot, V., \& Shearon, W. T. (1991). Budgetary participation, locus of control, and Mexican managerial performance and job satisfaction. The Accounting Review, 66, 80-99.

Fukuyama, F. (1995). Trust: the social virtues and the creation of prosperity. London: Penguin Books.

Gernon, H., \& Wallace, R. S. O. (1995). International accounting research: a review of its ecology, contending theories and methodologies. Journal of Accounting Literature, 14, 54-106.

Giddens, A. (1987). Structuralism, post-structuralism and the production of culture. In A. Giddens, \& J. Turner (Eds.), Social theory today (pp. 195-223). Cambridge: Polity Press.

Giddens, A. (1993). Sociology. Cambridge: Polity Press.

Harrison, G. L. (1992). The cross-cultural generalizability of the relation between participation, budget emphasis and job related attitudes. Accounting, Organizations and Society, 17, $1-15$.

Harrison, G. L. (1993). Reliance on accounting performance measures in superior evaluative style - the influence of national culture and personality. Accounting, Organizations and Society, 18, 319-339.

Harrison, G. L., McKinnon, J. L., Panchapakesan, S., \& Leung, M. (1994). The influence of culture on organizational design and planning and control in Australia and the United States compared with Singapore and Hong Kong. Journal of International Financial Management and Accounting, 5, 242-261.

Hofstede, G. H. (1980). Culture's consequences: international differences in work-related values. Beverly Hills, CA: Sage.

Hofstede, G. H. (1984). The cultural relativity of the quality of life concept. Academy of Management Review, 27, 389-398.

Hofstede, G. H., \& Bond, M. H. (1988). The confucius connection: from cultural roots to economic growth. Organizational Dynamics 16, 5-21.

Janelli, R. L. (1993). Making capitalism: the social and cultural construction of a South Korean conglomerate. Stanford, CA: Stanford University Press.

Kagitcibasi, C., \& Berry, J. W. (1989). Cross-cultural psychology: current research and trends. Annual Review of Psychology, 40, 493-531.

Kluckhohn, F. R., \& Strodtbeck, F. L. (1961). Variations in value orientations. Evanston, IL: Row, Peterson.

Kondo, D. (1990). Crafting selves: power, gender, and discourses of identity in a Japanese workplace. Chicago: University of Chicago Press.

Kraut, A. I. (1975). Some recent advances in cross-national management research. Academy of Management Journal, 18, 538-549.

Lachman, R., Nedd, A., \& Hinings, B. (1994). Analyzing crossnational management and organizations: a theoretical framework. Management Science, January, 40-55.

Lau, C. M., Low, L. C., \& Eggleton, I. R. C. (1995). The impact of reliance on accounting performance measures on 
job-related tension and managerial performance: additional evidence. Accounting, Organizations and Society, 20, 359381.

Lincoln, J. R., \& McBride, K. (1987). Japanese industrial organization in comparative perspective. Annual Review of Sociology, 13, 289-312.

Lincoln, J. R., Hanada, M., \& Olson, J. (1981). Cultural orientations and individual reactions to organizations: a study of employees of Japanese-owned firms. Administrative Science Quarterly, 26, 93-115.

Lincoln, J. R., Hanada, M., \& McBride, K. (1986). Organizational structures in Japanese and U.S. manufacturing. Administrative Science Quarterly, 31, 338-364.

Marsh, R. M., \& Mannari, H. (1976). Modernization and the Japanese factory. Princeton: Princeton University Press.

Merchant, K. A., Chow, C. W., \& Wu, A. (1995). Measurement, evaluation and reward of profit center managers: a crosscultural field study. Accounting, Organizations and Society, 20, 619-638.

Milani, K. W. (1975). The relationship of participation in budget-setting to industrial supervisor performance and attitudes: a field study. The Accounting Review, 50, 274-284.

Nussbaum-Gomes, M. (1994). The subconscious in organizational control: the case of Mitsubishi Heavy Industry. International Journal of Comparative Sociology, 35, 103-130.

O'Connor, N. G. (1995). The influence of organizational culture on the usefulness of budget participation by Singaporean-Chinese managers. Accounting, Organizations and Society, 20, 383-403.

Parsons, T., \& Shils, E. A. (1951). Values, motives and systems of action. In T. Parsons, \& E. A. Shils (Eds.), Toward a general theory of action (pp. 47-109). Cambridge, MA: Harvard University Press.

Pascale, R. T. (1978). Communication and decision making across cultures: Japanese and American comparisons. Administrative Science Quarterly, 23, 91-110.

Pelto, P. J. (1968). The difference between "tight" and "loose" societies. Transaction, April, 37-40.

Rohlen, T. (1974). For harmony and strength: Japanese whitecollar organizations in anthropological perspective. Los Angeles: University of California Press.

Rohner, R. P. (1984). Toward a conception of culture for crosscultural psychology. Journal of Cross-Cultural Psychology, $15,111-138$

Schwartz, S. H. (1994). Cultural dimensions of values: towards an understanding of national differences. In U. Kim, H. C. Triandis, C. Kagitcibasi, S. C. Choi \& G. Yoon (Eds.), Individualism and collectivism: theoretical and methodological issues (pp. 85-119). Thousand Oaks, CA: Sage.

Shearing, C. D., \& Ericson, R. V. (1991). Culture as figurative action. British Journal of Sociology, 42, 481-506.
Smith, P. B. (1992). Organizational behaviour and national cultures. British Journal of Management, 3, 39-51.

Smith, P. B., Dugan, S., \& Trompenaars, F. (1996). National culture and the values of organizational employees. Journal of Cross-Cultural Psychology, 27, 231-264.

Snodgrass, C., \& Grant, J. H. (1986). Cultural influences on strategic planning and control systems. Advances in Strategic Management, 4, 205-228.

Thompson, J. B. (1990). Ideology and modern culture: critical social theory in the era of mass communication. Cambridge: Polity Press.

Triandis, H. C. (1967). Interpersonal relations in international organizations. Journal of Organizational Behavior and Human Performance, 2, 26-55.

Triandis, H. C. (1988). Collectivism v. individualism: a reconceptualisation of a basic concept in cross-cultural social psychology. In G. K. Verma \& C. Bagley (Eds.), Cross-cultural studies of personality, attitudes, and cognition (pp. 60-95). New York: St. Martin's Press.

Triandis, H. C. (1989). The self and social behavior in differing cultural contexts. Psychological Review, 96, 506-520.

Triandis, H. C. (1993). Review of Hofstede, G., Culture and organizations: software of the mind (New York: McGraw-Hill, 1991). Administrative Science Quarterly, 38, 132-134.

Triandis, H. C. (1995). Individualism and collectivism. Boulder, CO: Westview Press.

Triandis, H. C., McCuster, C., Betancourt, H., Iwao, S., Leung, K., Salazar, J. M., Setiadi, B., Sinha, J. B. P., Touzard, H., \& Zaleski, Z. (1993). An etic-emic analysis of individualism and collectivism. Journal of Cross-Cultural Psychology, 24, 366-383.

Ueno, S., \& Sekaran, U. (1992). The influence of culture on budget control practices in the USA and Japan: an empirical study. Journal of International Business Studies, 23, 659-674.

Ueno, S., \& Wu, F. H. (1993). The comparative influence of culture on budget control practices in the United States and Japan. International Journal of Accounting, 28, 17-39.

Van Maanen, J. (1988). Tales of the field: on writing ethnography. Chicago: University of Chicago Press.

Vance, C. M., McClaine, S. R., Boje, D. M., \& Stage, D. (1992). An examination of the transferability of traditional performance appraisal principles across cultural boundaries. Management International Review, 32, 313-326.

Whitley, R. D. (1991). The social construction of business systems in East Asia. Organization Studies, 12, 1-28.

Whitt, J. D. (1979). Motivating lower level management of Mexican affiliates. Management Accounting, 60, 46-49.

Wuthnow, R., Hunter, J. D., Bergesen, A., \& Kurzweil, E. (1984). Cultural analysis: the work of Peter L. Berger, Mary Douglas, Michel Foucault and Jurgen Haberman. Boston, MA: Routledge \& Kegan Paul. 